\title{
The Romantic Author and the Romance Writer: Resisting Gendered Concepts of Creativity
}

Rebecca Tushnet

Georgetown University Law Center, rlt26@law.georgetown.edu

This paper can be downloaded free of charge from:

https://scholarship.law.georgetown.edu/facpub/1419

http://ssrn.com/abstract=2546339

Rebecca Tushnet, The Romantic Author and the Romance Writer: Resisting Gendered Concepts of Creativity, in DIVERSITY IN INTELLECTUAL PROPERTY, (Irene Calboli \& Srividhya Ragavan eds., Cambridge Univ. Press, forthcoming 2015)

This open-access article is brought to you by the Georgetown Law Library. Posted with permission of the author. Follow this and additional works at: https://scholarship.law.georgetown.edu/facpub

Part of the Fiction Commons, and the Intellectual Property Law Commons 


\section{4}

\section{The Romantic Author and the Romance Writer Resisting Gendered Concepts of Creativity}

\section{Rebecca Tushnet*}

\section{l.. Introduction}

Forms of creativity associated with women in Western culture, like cooking and fashion, receive less protection from intellectual property systems than forms of creativity associated with men, like painting and software. Just as with housework and childcare, female-associated forms of creativity have been expected to be provisioned naturally without need for the economic incentives provided by exclusive rights, even in an otherwise ever-more-commodified world.1 Within recognized forms of copyrightable creativity, while "authors" are

${ }^{*}$ Professor of Law, Georgetown University Law Center.

${ }^{1}$ A number of authors have examined the legal consequences of the gendering of creative activity and of copyright doctrines. E.g., Ann Bartow, Fair Use and the Fairer Sex: Gender, Feminism, and Copyright Law, 14 AM. U. J. GENDER Soc. Pol'Y \& L. 551 (2006); Dan L. Burk, Copyright and Feminism in Digital Media, 14 AM. U. J. GENDER SOC. POL'Y \& L. 519 (2006); Emily Chaloner, A Story of Her 
conventionally celebrated as valuable originators of works deserving legal protection, it likewise turns out that certain works aren't so valuable after all. The "Romantic author" - the independent original genius creating out of nothing - is not the romance writer, who merely retreads well-worn paths.

The concept of Romantic authorship has come under sustained analytic assault, as scholars have demonstrated that all works derive from other works. Creativity comes from insight and rearrangement, not from Godlike invention out of the void. However, these critiques have not led to much celebration of the other kind of author, the romance writer. Even sympathetic narratives often look

Own: A Feminist Critique of Copyright Law, 6 I/S: J. L. \& POL'Y FOR INFO. SOC'Y 221 (2010); Maureen B. Collins, Patchwork Protection: Copyright Law and Quilted Art, 9 J. MARSHALL REV. INTELL. PROP. L. 855 (2010); Rosemary J. Coombe, Critical Cultural Legal Studies, 10 YALE J. L. \& HUMAN. 463 (1998); Carys J. Craig, Reconstructing the Author-Self: Some Feminist Lessons for Copyright Law, 15 AM. U. J. GENDER SOC. POL'Y \& L. 207 (2007); Daniella Fischetti, Lost in Transcription: The Impact of Copyright Legislation on Female Folk Musicians of the Twentieth Century, 33 WOMEN'S RTS. L. REP. 285 (2012); K. J. Greene, Intellectual Property at the Intersection of Race and Gender: Lady Sings the Blues, 16 AM. U. J. GENDER SOC. POL'Y \& L. 365 (2008); Debora Halbert, Feminist Interpretations of Intellectual Property, 14 AM. U. J. GENDER SOC. POL'Y \& L. 431 (2006); Malla Pollack, Towards a Feminist Theory of the Public Domain, or Rejecting the Gendered Scope of United States Copyrightable and Patentable Subject Matter, 12 WM. \& MARYJ. WOMEN \& L. 603 (2006); Rebecca Tushnet, My Fair Ladies: Sex, Gender, and Fair Use in Copyright, 15 AM. U.J. GENDER SOC. POL'Y \& L. 273 (2007). 
elsewhere - to the kinds of creativity in which men are more likely to participate - to find models of situated, always-influenced authorship.

In this chapter, I examine one variant of the problem, in which certain arguments about copyright discount the value of forms that are predominantly produced and enjoyed by women. In particular, I focus on the heavily femaledominated area of media fandom, in which fans create new works of art based on existing television shows, movies, novels, and other popular works. So, for example, a fan might write a Harry Potter story that takes seriously the political oppression visited on nonhuman races like house elves and goblins, whose status is generally played for laughs in the published books and movies. Another fan might write a story in which Harry and Draco have a passionate romance - or one story might feature both themes. Many, although certainly not all, of the new works created within fandom focus on romance and sexuality, which is one reason that "fandom" is often associated with female sexual desire and excess, and therefore denigrated. Another way to say this is that fandom provides some, mainly female, audiences with works that directly address their perspectives and interests, unlike many of the cultural objects from which the fanworks are derived.

Fandom cultures offer new perspectives about the benefits of creativity, as well as about the distribution of those benefits. By rewriting popular 
narratives, fans open up new possibilities in sexual and gender relations, and learn to see themselves as valuable speakers. As a result, increasing the visibility of women's creative works, including explicitly transformative works based on specific copyrighted predecessors, is an important part of rejecting the fetishization of Romantic authorship and valuing diverse kinds of creativity. ${ }^{2}$ Copyright formally promises artistic neutrality, but without attention to the ways in which our ideas of creativity are gendered, it can't deliver on that promise.

\section{Rejecting the Romantic Author without Embracing the Romance Writer?}

Much copyright scholarship problematizes and deconstructs the idea of the Romantic author-genius creating from nothing. Scholars have addressed both the historical/cultural specificity of that idea (creativity was understood differently for a very long time and often still is outside of European traditions) ${ }^{3}$ and its empirical weaknesses even within the forms of artistry it purported to explain.

2 Cf. JoAnNa RuSS, How TO SUPPRESS WOMEN'S WRITING 76 (1983) (explaining that one way women's creativity is suppressed is by ignoring previous examples and making each woman artist seem unique and unusual).

3 See, e.g., Roland BARTHEs, IMAGE-MUSIC-TEXT 142-43 (1977) (discussing "author" as modern construction); MiCHEL FouCAULT, THE FOUCAULT READER 101 (Paul Rabinow ed., 1984). 
Others have specifically investigated the gender biases inherent in the concept of the unconstrained genius, who comes out of nowhere and relies on no one.4 Unfortunately, while discredited in academic discourses, the concept of the author-genius has succeeded brilliantly in the legal realm, justifying ever-greater expansions of copyright - often for the benefit of large corporations instead of garret-dwelling visionaries. 5

4 Deborah Halbert, Poaching and Plagiarizing: Property, Plagiarism, and Feminist Futures, in PERSPECTIVES ON PLAGIARISM AND INTELLECTUAL PROPERTY IN A POST-MODERN WORLD111, 113 (Lise Buranen \& Alice M. Roy eds., 1999) (discussing masculine gender of the mythical heroic author); Shelley Wright, $A$ Feminist Exploration of the Legal Protection of Art, 7 CAN. J. WOMEN \& L. 59, 7782 (1994).

5 See, e.g., James Boyle, Shamans, SofTWARE, aND SPLEENS: LAW AND THE CONSTRUCTION OF THE INFORMATION SOCIETYX-xiii (1996) (noting that invocations of the "romantic author" have contributed to a proliferation of intellectual property rights); Rosemary J. CoOmbe, THE CULTURAL LIFE OF INTELLECTUAL PROPERTIES 219 (1998); MARK RoSE, AUTHORS AND OWNERS: THE INVENTION OF COPYRIGHT 3 (1993) ("Copyright is founded on the concept of the unique individual who creates something original and is entitled to reap a profit from those labors. Until recently, the dominant modes of aesthetic thinking have shared the romantic and individualistic assumptions inscribed in copyright. But these assumptions obscure important truths about the processes of cultural production."); Keith Aoki, (Intellectual) Property and Sovereignty: Notes Toward a Cultural Geography of Authorship, 48 STAN. L. REV.1293, 1333-38 (1996); Peter Jaszi, Toward a Theory of Copyright: The Metamorphoses of "Authorship, "1991 DUKE L. J. 455, 456 [AU: missing publication year; Irene: the year is 1991, you can cite it as 1991 DUKE L. J. 455, 456 (1991) ]; PETER JASZI \& MARTHA WOODMANSEE, 
At the same time, not all authors of copyrightable works are equally respectable. As Joanna Russ documented in her monograph How to Suppress Women's Writing, there are a variety of venerable techniques to diminish the accomplishments of women (which can be repurposed for other groups as needed). 6 The romance genre, for example, is often the target of literary sneering, because of its associations with emotions and with femininity.7 Critics,

INTRODUCTION TO THE CONSTRUCTION OF AUTHORSHIP: TEXTUAL APPROPRIATION IN LAW AND LITERATURE 1, 3 (Martha Woodmansee \& Peter Jaszi eds., 1994) (copyright doctrine is smitten with the "heroic self-presentation of Romantic poets"); Martha Woodmansee, On the Author Effect: Recovering Collectivity, 10 CARDOZO ARTS \& ENT. L. J. 279, 292 (1992) ("[T] he law has yet to be affected by the 'critique of authorship' initiated by Foucault .... [I]t would seem that as creative production becomes more corporate, collective, and collaborative, the law invokes the Romantic author all the more insistently.").

${ }^{6}$ Russ, supra note 2, at 76 ("She didn't write it. She wrote it, but she shouldn't have. She wrote it, but look what she wrote about. She wrote it, but 'she' isn't really an artist and 'it' isn't really serious, of the right genre - i.e., really art .... She wrote it, but there are very few of her.").

7 TANia Modleski, LoVING With A VENGEANCE: MASS-PRODUCED FANTASIES FOR WOMEN 11-15 (1982) (reporting disproportionately harsh judgments compared to "male" genres); JANicE RADWAY, READING THE ROMANCE: WOMEN, PATRIARCHY, AND POPULAR LITERATURE 8-10 (1984) (noting dismissiveness of critics); Eric Murphy Selinger \& Sarah S. G. Frantz, Introduction: New Approaches to Popular Romance Fiction, in NEW APPROACHES TO POPULAR ROMANCE FICTION: CRITICAL ESSAYS 1, 2-3 (Sarah S. G. Frantz \& Eric Murphy Selinger eds., 2012) (the genre's bad reputation is related to a "profoundly gendered anxiety over mass culture more generally. In a context where 'feminine qualities - emotion, sentiment, passivity 
both legal and literary, have often assumed that romance novels are interchangeable consumables, "mass produced" in a way that other books somehow aren't. "[A]ssessments of romance fiction have often viewed these novels as if they were reprints of one photograph"8 - a particularly telling analogy in the context of copyright, where reprints would not be entitled to any independent protection. Even fair-use friendly academics can slip into stereotype, treating romances as meaningless commodities, more like chewing gum than literature, 9 "wholly lacking in scholarly or research significance."10 Others see romances, and their readers, as not just meaningless but worthless. ${ }^{11}$

- are used to signify the worthlessness of mass culture,' popular romance fiction has been triply shameful: it is, after all, a form overwhelmingly written and read by women, at least since the last century; a form dedicated to the exploration of emotion, including sentiment; and a form whose publishers and authors have embraced the mass-culture marketplace, eschewing literary difficulty and the aesthetics of estrangement even as modernism made these terms of unqualified praise." (footnotes and citation omitted)).

8 Mary Bly, On Popular Romance, J. R. Ward, and the Limits of Genre Study, in NEWAPPROACHES TO POPULAR ROMANCE FICTION, supra note 7, at 60, 62.

${ }^{9}$ Glynn Lunney, Copyright, Private Copying, and Discrete Public Goods, 12 TUL. J. TECH. \& INTELL. PROP. 1, 19 (2009) (describing romance novels as examples of "read-and-toss" works whose consumers "might not care about which particular work they receive," but "may simply want another unit in a relatively homogenous stream of works").

10 Pamela Samuelson, Google Book Search and the Future of Books in Cyberspace, 94 MINN. L. REV. 1308, 1334 n. 134 (2010) (“Google's license from the settlement class allows it to scan not only many books for GBS that may be 
There's even legal commentary that blithely writes off romances and fantasies as so trivial and irrelevant to real life that there is no such thing as fair use of them:

The Harry Potter series of books, for example, are works of pure fancy. These books certainly deal with issues of human nature addressing subjects like the struggle between good and evil, selfawareness, and coming of age - but they are set in a parallel universe. They make no explicit attempt to address important social or political topics, and as such they should be free from subsequent use [for purposes of fair use analysis].

Genre fiction (horror, mystery, romance) is typically about the plot of the story or about the main character's experience within the setting developed in the story. These works deal with human nature but generally lack social commentary. Romance

wholly lacking in scholarly or research significance (e.g., say, Harlequin romance novels), but also duplicates of books already in the corpus."). But see Ann Bartow, Fair Use and the Fairer Sex: Gender, Feminism, and Copyright Law, 14 AM. U.J. GENDER SOC. POL'Y \& L. 551, 581 (2006) (arguing against dismissiveness toward romance novels, especially as compared to other popular genres).

11 See, e.g., M. Todd Henderson, The Nanny Corporation, 76 U. CHI. L. REV. 1517,1531 (2009) ("Even reading romance novels, after all, may impose costs on others, since presumably the less well-educated are a net drain on society."). 
novels, for example, deal with love, lust, romance, and human relationships. These works, however, are largely divorced from the issues and problems of the real world.12

Compounding this disrespect, in the case of fanworks, is the (gendered) disdain with which many commentators regard work performed for love instead of for money. In a decision expanding the scope of copyright fair use, Justice Souter quoted Samuel Johnson's statement that “[n]o man but a blockhead ever wrote except for money" with approval. ${ }^{13}$ It is not incidental that Johnson's writer, and Souter's, is male, whether he's a blockhead or not.

Nonetheless, despite this prominent denigration of the noncommercial in order to valorize the commercial, American copyright law has taken a different approach to fair use than that advocated by the man who thinks that love, lust, and human relationships have nothing to do with the real world. Recently, fair use cases have begun to give more freedom to works that clearly borrow from particular antecedents. The doctrine of transformative fair use specifically honors the authorship of a second-comer who uses an existing work to create

12 Michael Coblenz, Not for Entertainment Only: Fair Use and Fiction as Social Commentary, 16 UCLA ENT. L. REV. 265, 302 (2009).

${ }^{13}$ Campbell v. Acuff-Rose Music, Inc., 510 U.S. 569, 584 (1994) (quoting SAMUEL JOHNSON, 3 BOSWELL'S LIFE OF JOHNSON 19 (George Hill ed., 1934) (alteration [AU: do you mean the brackets?; Irene: YES] in original)). 
something new. Courts still honor "creativity" over "copying," but at least creativity is recognized in the very act of appropriation when the result is a new meaning or message. Quoting an influential article by Judge Pierre Leval, the Second Circuit explained that "if [the original work] is used as raw material, transformed in the creation of new information, new aesthetics, new insights and understandings - this is the very type of activity that the fair use doctrine intends to protect for the enrichment of society."14

This trend is not without its dangers. The "raw material" trope has the potential to re-inscribe the subject/object, nature/culture, raw/cooked binaries that have often been used to position women as lesser than men. And litigated fair use cases often do find fair use when women's bodies have been used as the raw material for transformations worked by men. ${ }^{15}$ Indeed, the Second Circuit opinion quoted in the previous paragraph proceeded to find that Richard Prince's juxtaposition of artistic photographs of Jamaican landscapes and men in dignified poses with soft-porn photos of naked women in sexualized poses created exactly the kind of new meaning that justified a finding of fair use. The question is whether fair use can be more than that: whether it can protect

14 Cariou v. Prince, 714 F.3d 694, 706 (2d Cir. 2013).

15 See Tushnet, supra note 1, at 273-85. 
diversity by recognizing forms of creativity that women are more likely to engage in.

Right now, the use of mostly male exemplars in conversations about copyright reform distorts our understanding of the potentials and benefits of remix (works created using parts of existing works) and user-generated content (works created and distributed outside traditional content industry settings). For example, a recent Green Paper from the Department of Commerce suggested that the legal framework for remix might need updating, especially given the rise of new licensing mechanisms. ${ }^{16}$ By identifying the object of concern as "remix," the Green Paper used terminology that seemed gender neutral; its specific examples nonetheless came solely from male artists. ${ }^{17}$ This is far from unusual. In another typical instance, RIP: A Remix Manifesto, a documentary lauding remixers and criticizing the scope of contemporary copyright law, focuses on the male DJ who performs under the (ironic) name Girl Talk. The documentary only features a few speaking "girls," one of whom is a technologically limited

16 Department of Commerce Internet Policy Task Force, Copyright Policy, CREATivity, AND InNOVATION In THE Digital ECONOMy 28-29 (July 2013) [hereinafter GREEN PAPER].

17 See id. at 28 n. 143 (DJ Danger Mouse); 29 n. 148 (Kanye West). 
representative of current copyright law and another of whom is presented only as Girl Talk's girlfriend.18

The focus on men is unrepresentative in the plainest sense. Although reliable statistics are hard to come by, fanworks are incredibly common forms of remix, and fanwork production is a female-dominated form, at least among English speakers. ${ }^{19}$ One large fan fiction website, Fanfiction.net, contains millions

18 See Laura J. Murray, RiP: A Remix Manifesto, Culture Machine, June 15, 2009.

19 U.S. Copyright Office, Public Hearings: Exemption to Prohibition on Circumvention of Copyright Protection Systems for Access Control Technologies 0108.20-0111.15 (May 7, 2009) (statement of Francesca Coppa), available at http://www.copyright.gov/1201/hearings/2009/transcripts/1201-5-7-09.txt; Henry Jenkins, Abigail Derecho, Gender and Fan Culture (Round Eight, Part One): Abigail Derecho and Christian McCrea, ConfEssions of AN ACA-FAn (THE OfFicial BloG OF HENRY JeNKIS) (Jul. 26, 2007), available at http://henryjenkins.org/2007/07/gender and fan culture round e.html ("[D]igital remix culture owes a substantial debt to minority discourse. Three genres of digital remix were pioneered between 1986 and 1996: digital music sampling, video game mods, and online fanfic. Of those three, the first was the invention of African American men (most of them were men, not all) and the third was the invention of white American women (most of them were white, most of them were women, not all).... It is vital that we media (especially digital media) scholars depict accurately the history of women media fans as not only highly competent, but inventive in their uses of a wide array of technological platforms and tools."). 
of stories based on sources from Harry Potter to Everything Is Illuminated and almost anything else imaginable.

Another prominent celebration of remix culture does include a lot of women, but ends up minimizing the gender implications of its own evidence. Clay Shirky's Cognitive Surplus is a rousing defense of the affordances of digital cultures. Shirky provides multiple examples of social and civic participation enabled by online connections - many of them organized by women, created at least initially by shared love of a popular culture performer or artifact. In other words, fandom brought largely female groups together and empowered them to engage in further activism.

Shirky calls attention to Mimi Ito's work on South Korean protests against American beef imports, significant enough that they threatened the entire South Korean government and led to the firing of the cabinet, along with an apology from the president. The protesters numbered over a million, an estimated 60-70 percent of which were teens, mostly teenage girls. Many were fans of a boy band and organized using fannish groups and websites. Ito reports, "young women fans of this boy group were mobilizing to attend the protests. They carried placards saying 'We don't want our boys to get sick because of mad[] cows.' Their 
participation in the protests was grounded less in the concrete conditions of their everyday lives, and more in their solidarity with a shared media fandom."20

As Ito concludes, "you should never underestimate the power of peer-topeer social communication and the bonding force of popular culture. Although so much of what kids are doing online may look trivial and frivolous, what they are doing is building the capacity to connect, to communicate, and ultimately, to mobilize." Ito concludes that "trivial" social spaces are an on-ramp for engagement of all kinds: seeing oneself as a producer entitled to make new things and to comment on others' works is an important way of seeing oneself as a citizen. ${ }^{21}$

The same dynamics of fandom both providing pleasure and spurring activism appear in another story to which Shirky returns several times: the charitable fundraising performed by (female) fans of Josh Groban. And then Shirky reassures us that we don't have to worry about organizing our social or technological worlds to support fannish engagement, because it will naturally be produced, like housework and childcare. It's not that there's anything wrong with fan fiction, he contends, but "anything at the personal and communal end of

${ }^{20}$ Mimi Ito, Media Literacy and Social Action in a Post-Pokemon World, Miмi ITo (Feb. 24, 2009), available at http://www.itofisher.com/mito/publications/media literacy.html.

${ }^{21} \mathrm{Id}$. 
the spectrum isn't in much danger of going away, or even of being under provisioned."22 If only that were true, I wouldn't be as troubled as I am by Shirky's rhetorical choices. But laws like the Digital Millennium Copyright Act, which prohibits taking even small clips from DVDs for purposes of making remixes, and the anti-anonymity measures taken by multiple governments (not for nothing, including South Korea) don't leave fannish spaces untouched. A culture or a legal system that discourages people from commenting on and remixing the things they love, in communities who love the same thing they do, also discourages them from commenting on and remixing everything else.

Given this history of under-visibility, I want to examine the benefits of female-dominated fandom spaces in more detail, in order to explain why they deserve special consideration in conversations about remix and fair use.

\section{IIII.: Defending Women's Work}

The common error of dismissing romances and fanworks as unimportant and uncreative comes in part from judging a whole genre by its worst or average exemplars, which is very much like judging English plays by their worst or average exemplars without also acknowledging the existence of Shakespeare

22 Clay Shirky, Cognitive SuRplus: How TeChnology Makes Consumers into COLLABORATORS 175 (2010). 
(who, of course, copied heavily himself). This judgment by outsiders is made easier by associations with femininity, triviality, and particularly adolescence.

There are reasons to reject such negative judgments even aside from aesthetics:

One more word on that "stereotype" of fanfic as the domain of female teenagers - of course it's an insult to adults who find fanfic to be a unique mode of criticism or a zero-g literary playspace or, sure, a sexual outlet; it's also an insult to female teenagers, a group who've seen enough insults, I think. The teen fic writer is finding her literary voice, learning to comment on mainstream fictions, finding a way to express her sexuality that's not entirely about recreating herself as a visual object for others' consumption. She is rarely a very good writer, because she's usually a very new one, but it's harsh to make her up into a symbol of writing as "fantasies" of "unlikely romantic pairings" and nothing more. She has an intellectual life, even if it's sometimes more potential than realized. 23

23 thesmallmachine, Comment to Fan fiction and legitimacy, SALON (Feb. 15, 2011), available at http://letters.salon.com/books/laura miller/2011/02/15/last ringbearer/per malink/576896f5b24f9130b7d575bfb6bca20a.html. 
But there are also aesthetic defenses worth making. There are brilliant artworks within fandom, from comedies of manners to vicious deconstructions of misogynist tropes, from breathtaking erotica to skin-crawling horror. Within any genre, experienced audiences make extremely careful distinctions and judgments, and this is as true of fanworks as it is of conventionally published romances. Moreover, familiarity with the conventions of a genre allows authors to innovate as well as to produce excellent examples within the form. ${ }^{24}$ Even though the more than 660,000 fanworks based on Harry Potter on Fanfiction.net may all be about the same general group of characters or fantasy world, that doesn't make them interchangeable. (Some of these stories invent new characters, while others take Rowlings's characters and move them out of Hogwarts and the wizarding world entirely - Harry Potter is the starting point, and fans can go virtually anywhere from there.)

As critics of the Romantic author-construct have told us, working within a set of constraints is consistent with originality. Hamlet, for example, is a perfectly

24 See Selinger \& Frantz, supra note 7, at 6-7 ("[W] hether the genre is romance, science fiction, or mystery/detective fiction, competent readers (... 'fans') take their pleasure in individual texts by reading them at once within and against the traditions and possibilities of that system .... The 'insatiable readers' of popular romance fiction ... are hardly indiscriminate consumers. Indeed, they may grade harder than most literature professors and reviewers of literary fiction."). 
good example of the genre of revenge tragedy, and also blazingly original. Genres offer opportunities to invent. 25 This is, in fact, what formal copyright doctrine purports to recognize as well: ideas are unprotected; it's variation in expression that we seek, not novelty of ideas.

Yet modern copyright law has discouraged overt reliance on earlier works, now that the reproduction and derivative works rights encompass far more than exact copying and translation into a new medium. Expansive rights conflict with the human propensity to respond to stories by altering and retelling them. For example, Alice Randall's account of how she came to write her retelling of Gone with the Wind offers a compelling illustration of why people rewrite stories to empower themselves. As she explains, as a young girl she loved the television series Batman, but "hated the fact that no one who looked like me was in the story." Soon, she began to write new Batman stories, with herself as Bat Girl. “My Bat Girl wasn't a sidekick; she was a catalyst; every time I wrote her into a story, she changed its ending. When they took Batman off the air, I made my first long-distance phone call. I wanted to save the show."

25 Bly, supra note 8, at 62-63; An Goris, Loving by the Book: Voice and Romance Authorship, in NEW APPROACHES TO POPULAR ROMANCE FICTION: CRITICAL ESSAYS 73, 76 (Sarah S. G. Frantz \& Eric Murphy Selinger eds., 2012) (discussing the importance of integrating familiar structures with innovation - giving the reader "what she wants and expects, but differently"). 
Randall went through the same love-hate process with Gone with the Wind: "I had to overlook racist stereotyping and Klan whitewashing to appreciate the ambitious, resilient, hardworking, hard-loving character who is Scarlett. Like so many others, I managed to do it. Then one day, rereading the novel, an enormous question arose for me from the center of the text. Where are the mulattos on Tara? Where is Scarlett's half-sister? Almost immediately I knew I had to tell her story, tell the story that hadn't been told. Tell it because the silence injured me."26 Randall's experience demonstrates many of the benefits and affordances of fandom: the love (and pain) that drove her rewriting also impelled her to intervene in the world in other ways, by taking the radical step for a young child of making a long-distance phone call. Because she'd become so engaged with Batman and Bat Girl, she believed her opinions mattered. Later, she followed the same pattern and was willing to fight an extensive legal battle to keep speaking about Gone With the Wind.

Randall's story is unusual only in that she found a commercial publisher. Historically, minority groups are disproportionately likely to rewrite popular texts for their own satisfaction, because they need to do so to see themselves

${ }^{26}$ A Conversation with Alice Randall, Houghton Mifflin HaRCourT, available at http://www.hmhbooks.com/readers guides/wind done gone/index2.shtml\#co nversation (last visited Nov. 11, 2013). 
fully represented: women;27 gay, lesbian, bisexual, transgender, and queer people ${ }^{28}$ and racial minorities of all sexes and orientations ${ }^{29}$ routinely create

27 See Kristina Busse, Introduction, 48 CINEMA J. 104, 105-06 (2009); Francesca Coppa, A Fannish Taxonomy of Hotness, 48 CINEMA J. 107, 107 (2009) [hereinafter Coppa, Taxonomy]; Micole, Women's Art and “Women's Work”, Ambling Along the Aqueduct, (Aug. 29, 2007), available at http://aqueductpress.blogspot.com/2007/08/womens-art-and-womenswork.html.

${ }^{28}$ Fan videos have been identified as a queer genre. See Julie Levin Russo, User-Penetrated Content: Fan Video in the Age of Convergence, 48 CINEMA J. 125, 126 (2009) ("[Fan videos] celebrate, critique, and de- or reconstruct mass media ... engaging the source via its own images ... and visual language. In many cases, they render queer dimensions of these sources visible by telling stories of samesex romance (known as 'slash') through sophisticated viewing and editing techniques." (citation omitted)); cf. Sonia K. Katyal, Performance, Property, and the Slashing of Gender in Fan Fiction, 14 AM. U. J. GENDER SOC. POL'Y \& L. 461, 46869 (2006) (discussing the role of slash in making queer meanings).

29 See Olufunmilayo B. Arewa, From J. C. Bach to Hip Hop: Musical Borrowing, Copyright and Cultural Context, 84 N. C. L. REV. 547, 561, 622 (2006); K. J. Greene, "Copynorms," Black Cultural Production, and the Debate over African-American Reparations, 25 CARDOZO ARTS \& ENT. L.J. 1179, 1186 (2008); Sherri Carl Hampel, Note, Are Samplers Getting a Bum Rap?: Copyright Infringement or Technological Creativity?, 1992 U. ILL. L. REV. 559, 588-89 (1992) ("The rap genre is based on and built up around digital sampling. Rap began, before sampling existed, by singing original lyrics over cassette tapes of songs or rhythm tracks."); Olufunmilayo B. Arewa, Seeing but Not Hearing Music: How Copyright Got (And Didn't Get) the Blues 55 (Oct. 14, 2008) (manuscript), available at http://law.scu.edu/wpcontent/uploads/hightech/Seeing $\% 20$ But $\% 20$ Not $\% 20$ Hearing $\% 20$ Music by 
remixes and fanworks that change the focus of popular narratives. 30 The first original prose fiction by a woman in English was explicitly based on an existing work in order to respond to it, as was the first published play by a woman in English. These works are read today as early feminist works because they critique the patriarchal society of the time. Fanfiction follows in these footsteps. ${ }^{31}$ Transforming existing stories is a particularly appealing form in part because it readily permits critical analysis of existing structures - by showing

\%200lufunmilayo\%20B \%20Arewa.pdf ("[I]ncumbent creators have been permitted to borrow from certain traditions, particularly traditions from groups such as African Americans, who historically have been at the bottom of most societal hierarchies of status and power. Many of these incumbents may then be able to use copyright to block borrowings from their works, despite the fact that such works borrow extensively. The operation of copyright as a property rule also disfavors certain aesthetics of cultural production, including those that use extensive borrowing, particularly when borrowing is undertaken by those with relatively low status, limited resources or less power relative to those from whom they borrow.").

30 Abigail Derecho, Archontic Literature: A Definition, a History, and Several Theories of Fan Fiction, in FAN FICTION AND FAN COMMUNITIES IN THE AGE OF THE INTERNET61, 67 (Karen Hellekson \& Kristina Busse eds., 2006) ("[M]any subordinate cultures throughout history, especially women and ethnic minorities, have chosen to record and/or publicize their opinions by writing archontic [explicitly intertextual] literature.").

31 Id. at 71. 
possibilities and alternatives, remixes demonstrate that there is no single, necessary story. 32

${ }^{32}$ As fan N. J. B. wrote to the Organization for Transformative Works (OTW),

[Fanfiction] is the response to many who feel alienated by the dominant paradigm (indeed, who at times does not feel alienated, for there is no such thing as a "normal" person.) Fanfiction is the supportive, creative space for blacks who after seeing a movie in which all the main characters are white, thinks, "I would do it differently, and here's how." Fanfiction is for the girls who read a comic book in which the heroes are all men, and imagines herself as Captain America. Fanfiction is for all those who watch/listen to/read a story and cannot empathize with the characters as they are, but see potential in tweaking, recreating, and re-imagining the story to fit and resonate with their own lives. Finally, fanfiction is for all groups of people misrepresented in our mass media, and it gives them a space to create alternatives which are as empowering for the producer as the consumer. 
These revisions are also necessary because Alice Randall's story of exclusion is so common. Women are significantly underrepresented in mainstream media. As Geena Davis summarized the research:

The basics are that for every one female-speaking character in family-rated films (G, PG and PG-13), there are roughly three male characters; that crowd and group scenes in these films - liveaction and animated - contain only $17 \%$ female characters; and that the ratio of male-female characters has been exactly the same since 1946. Throw in the hyper-sexualization of many of the female characters that are there, even in G-rated movies, and their lack of occupations and aspirations and you get the picture. 33

OTW's Legal Committee, Comments to the NTIA/PTO, 30 (Nov. 17, 2013), available at http://transformativeworks.org/sites/default/files/Comments\%20of\%200TW \%20to\%20PTO-NTIA.pdf.

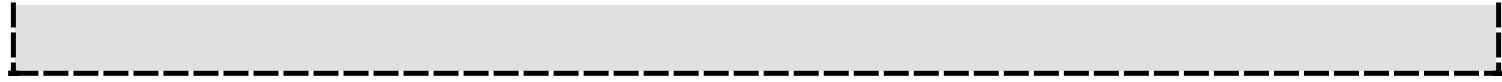

33 Geena Davis, Geena Davis' Two Easy Steps To Make Hollywood Less Sexist (Guest Column), Hollywood RePorTer (Dec. 11, 2013), available at http://www.hollywoodreporter.com/news/geena-davis-two-easy-steps$\underline{664573}$. 
The women who do appear are significantly younger than their male counterparts, and older women are rare. ${ }^{34}$ The same is true of children's literature, where only 31 percent of the books published from 1900-2000 had female central characters. ${ }^{35}$ And the pattern repeats with prime-time and children's television. Women hold only 20-25 percent of the jobs in film and television, even though we're roughly half of the American workforce. 36 Television shows are cancelled for having too many strong, interesting female characters. ${ }^{37}$

34 Anupam Chander \& Madhavi Sunder, Everyone's a Superhero: A Cultural Theory of 'Mary Sue' Fan Fiction as Fair Use, 95 CALIF. L. REV. 597, 603 (2007).

35 Janice McCabe et al., Gender in Twentieth-Century Children's Books: Patterns of Disparity in Titles and Central Characters, 25 GENDER \& SOCIETY 197 (2011).

36 See Stacy L. Smith et al., Gender Roles \& Occupations: A Look at Character Attributes and Job-Related Aspirations in Film and Television, SEE JANE (n.d.), available at http://www.seejane.org/downloads/KeyFindings GenderRoles.pdf (last visited Mar. 8, 2014).

37 Inkoo Kang, Blood-Boiler of the Day: TV Show Canceled for Having Too Many Smart, Interesting Girl Characters, Women AND Hollywood BloG (Dec. 19, 2013), available at http://blogs.indiewire.com/womenandhollywood/bloodboiler-of-the-day-tv-show-canceled-for-having-too-many-smart-interesting-girlcharacters (reporting on writer Paul Dini's report of why his show Tower Prep was cancelled; executives wanted boy viewers, not girls; "Dini relates that higher-ups at the cable network urged him to focus his storylines on his male 
These absences and stereotypes are not benign. Children readily acquire gender and racial stereotypes from media representations. ${ }^{38}$ Even adults are swayed by exposure to stereotypical portrayals, although they may be unaware of the effects. ${ }^{39}$ In this context, fanworks can be uniquely liberating, fighting back against these exclusions by offering audiences hundreds of works in which characters like them are the focus. "Rewriting the popular narrative becomes an act of not only trying to change popular understandings, but also an act of selfempowerment."

Mainstream culture's dismissiveness of fandom and femininity, while harmful, also opens up space for innovation - it's easier to experiment when no characters and make his female characters 'one step behind the boys, not as smart as the boys, not as interesting as the boys'”).

${ }^{38}$ Chander \& Sunder, supra note 34 , at 606-07.

39 Id. at 607; see also, e.g., Claude Steele, A Threat in the Air: How Stereotypes Shape Intellectual Identity and Performance, 52 AM. PSYCHOL. 613 (1997) (discussing the concept of stereotype threat - internalized reaction to perceived stereotypes - and the research revealing that evoking stereotypes dramatically depress the standardized test performance of women and AfricanAmericans).

40 Chander \& Sunder, supra note 34, at 619-20; see also, e.g., Nilanjana Dasgupta \& Anthony G. Greenwald, On the Malleability of Automatic Attitudes: Combating Automatic Prejudice with Images of Admired and Disliked Individuals, 81 J. PERSONALITY \& SOC. PSYCHOL. 800 (2001) (explaining that images of admirable members of minority groups can counter the effects of stereotypes). 
one takes you seriously. As Rebecca Traister wrote of soap operas, in any "feminized (and thereby marginalized) genre," the borders will be unpatrolled. ${ }^{41}$ Freedom from the constraints of "publishability" that dominate commercial publication allows fans to explore whatever topics, in whatever style and at whatever length, interest them - and find at least a few like-minded souls. ${ }^{42}$ And one common result is texts that address sex and gender roles.

For example, "slash," broadly speaking, is a genre of art, fiction, and video that takes characters who are usually shown in official texts as heterosexual and portrays them in same-sex relationships. ${ }^{43}$ This contrast between the official and the unofficial challenges mainstream gender norms and stereotypes, allowing fans to identify alternative sexualities everywhere and anywhere - same-sex relationships or other non-normative sexualities or gender identities can be consistent with being a macho cop or a space explorer. As Sonia Katyal explains:

By taking traditional male heroes and reworking their characters and performances, slash writers are able to dissect, appropriate, and then

41 Rebecca Traister, The Soap Opera Is Dead! Long Live the Soap Opera!, N.Y. Times (Sep. 23, 2011), available at https://www.nytimes.com/2011/09/25/magazine/the-soap-opera-is-deadlong-live-the-soap-opera.html?ref=magazine.

42 Catherine Tosenberger, Mature Poets Steal: Children's Literature and the Unpublishability of Fanfiction, 39 CHILDREN'S LITERATURE ASS'N Q. 4, 22 (2014).

43 Katyal, supra note 28, at 467. 
deconstruct the various elements of male dominance. For example, in stark opposition to the typical dominant male/passive female theme one often sees in popular culture texts, slash depicts two equals involved in a romantic relationship. ${ }^{44}$

By rewriting official texts, slash writers reimagine what is possible for sexuality and gender roles. 45

Slash, according to Joanna Russ, addresses women's desires for "love and sex as women want them, whether with a man or with another woman." This is a creative response to desire in a context of sexual and sexualized oppression. It is not simply based in a desire to enact what's portrayed in the stories: female slash writers don't literally wish to become male any more than they literally want their dear ones to bleed and die in their arms or to die with their lovers. What they do want is sexual intensity, sexual enjoyment, the freedom to choose, a love that is entirely free of the culture's whole discourse of gender and sex roles, and a situation in which it is safe to let go and allows oneself to become emotionally and sexually vulnerable .... They also want (and I find

44 Id. at 486.

45 Id. at 489. 
this absolutely fascinating and aesthetically very valuable) to create images of male bodies as objects of desire. One of the worst things forced on us in the name of "femininity" is passivity, a distortion created by the heterosexual institution and a guarantee of sexual and human paralysis. The writers and readers of these fantasies can do what most of us can't do in reality (certainly not heterosexual reality), that is they can act sexually at their own pace and under conditions they themselves have chosen. ${ }^{46}$ Another fan characterized slash as "women stepping forward to describe their own erotics, because our culture silences female desire as effectively as it silences queer desire." ${ }^{47}$ Slash is only one of the possibilities available in remix, but it is a powerful one, especially for people who are dissatisfied with rigid gender roles for both men and women. ${ }^{48}$

46 JoAnna Russ, Pornography BY WOMEn For Women, With LoVE, IN MAGIC Mommas, TREMbling Sisters, PuRITANS AND PERVERTS 80-99 (1985); see also Henry JENKINS, TEXTUAL POACHERS 1, 189 (1992) (slash is "a reaction against the construction of male sexuality on television and in pornography; slash invites us to imagine something akin to the liberating transgression of gender hierarchy").

47 Alexis Lothian et al., Yearning Void and Infinite Potential: Online Slash Fandom as Queer Female Space, 45 ENG. LANG. NoTES 103, 106 (2007). 


\section{See Henry Jenkins, Confessions of a Male Slash Fan, 1 STRANGE}

BEDFELLOWS (May 1993): [AU: This whole passage is quoted in the next chapter as well, and the whole of Chapter 15 is about slash. What about putting a crossreference here to Chapter 15 of this volume instead of citing and quoting Jenkins? RT: Absolutely, please do so.]

When I try to explain slash to non-fans, I often reference that moment in Star Trek: The Wrath of Khan where Spock is dying and Kirk stands there, a wall of glass separating the two longtime buddies. Both of them are reaching out towards each other, their hands pressed hard against the glass, trying to establish physical contact. They both have so much they want to say and so little time to say it. Spock calls Kirk his friend, the fullest expression of their feelings anywhere in the series. Almost everyone who watches that scene feels the passion the two men share, the hunger for something more than what they are allowed. And, I tell my nonfan listeners, slash is what happens when you take away the glass. The glass, for me, is often more social than physical; the glass represents those aspects of traditional masculinity which prevent emotional expressiveness or physical intimacy between men, which block the possibility of true male friendship.

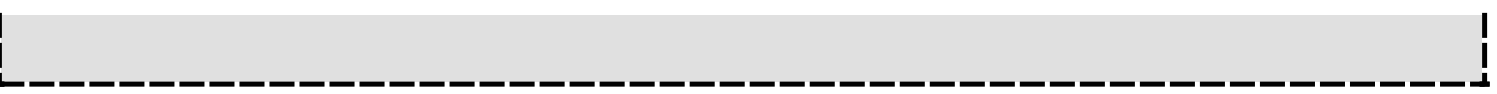


As Russ continues, slash "reject[s] the notion that gender roles are fixed and predetermined and embraces the idea that sexuality can be fluid and filled with various erotic possibilities." 49 Because slash usually starts with characters who are presumptively heterosexual in the canonical versions, it suggests that everyone and anyone could experience same-sex desire, or equality in sexual and romantic relationships. 50 One fan's experiences concretize why it is the rewriting, not just the writing, of slash, that is so important. Coming from a conservative east Texas background, Chelsea S. found her sexuality hard to admit even to herself. But in slash, she saw:

one of my favorite television characters, one with whom I identified deeply, recast as a bisexual man. His character was not significantly altered, he didn't suddenly become something unrecognizable. The stories I read featured him having more or

${ }^{49}$ Katyal, supra note 28, at 486.

50 Anne Kustritz, Slashing the Romance Narrative, 26 J. AM. CULTURE 371, 377 (2003) ("[Slash writers] tear down the traditional formula of romance novels and films that negotiate the submission of a heroine to a hero by instead negotiating the complicated power balance between two equally dominant, independent, and masculine characters. This friendship-based love narrative, along with an equality-centered relationship dynamic, is the overwhelming preoccupation of slash narratives."). 
less the same adventures he always had. It was the first step to greater tolerance and greater self -acceptance for me.51

Another common variant in fanworks is the "Mary Sue," a power fantasy in which a female character representing the author joins the main characters (almost all male) and proves to be the best of them all. Madhavi Sunder and Anupam Chander point out that this type of rewriting offers a partial antidote to a media that neglects or marginalizes certain groups. Victims of prejudice often internalize its claims; indeed, oppressive societies have often relied on this psychological trick to maintain hierarchies. A process of consciousness-raising and selfempowerment requires that one recognize one's own potential, even if others do not. ... Mary Sues help the writer claim agency against a popular culture that repeatedly denies it. 52

Given the social science evidence on the importance of representations, Mary Sue fanworks can help combat the toxic effects of stereotyping and underrepresentation. 53

51 OTW, supra note 32 , at 34.

52 Chander \& Sunder, supra note 34, at 608 (footnotes omitted).

53 See id. at 599-600, 610; see also id. at 613 (Mary Sues "comment on or criticize the original, while at the same time creat[ing] something new. They highlight the absence of society's marginal voices in the original works, the 
Indeed, Alice Randall's The Wind Done Gone challenges Gone with the Wind s racism and sexism precisely through the addition of a beautiful, accomplished African-American character in the Mary Sue mold. ${ }^{54}$ Randall's work fits into a larger ongoing tradition of rewriting to challenge conventional racial narratives and stereotypes as well as gender norms. 55 While media fandoms are in no sense utopias of equality, many fans have increasingly attended to intersectionality and issues of social justice in representation beyond

stereotyped actions or inactions of certain characters, and the orthodoxy of social relationships in the original.").

54 Id. at 601.

55 Derecho, supra note 30, at 69 (explaining that many authors have used existing works to critique racism and colonialism, including many versions of Shakespeare's Tempest, multiple retellings of Jane Eyre (including Jean Rhys' Wide Sargasso Sea), rewritings of Robinson Crusoe, Sena Jeter Naslund's Ahab's Wife (retelling Moby Dick), Alice Randall's The Wind Done Gone, and Nancy Rawles's My Jim (retelling Huckleberry Finn from the perspective of the slave Jim and his wife)). For noncommercial, fan versions, see, e.g., Remember Us?, TELAND (July 21, 2007), available at http://www.teland.com/remember/index2.html (characters of color archive); Yahtzee, Them Mean OI', Low-Down, Lando Calrissian Blues, ChivalRy IS DeAD, available at http://www.thechicagoloop.net/yahtzee/chivalry/chivfic/LCBlues.htm (in which a number of African-American sidekicks from various television shows meet and commiserate) (last visited Nov. 12, 2013). 
sexism.56 In media fandom, the common practice of "racebending" replaces white heroes with nonwhite casts, envisioning how the story would change if white people were no longer the default. ${ }^{57}$ One vidder of color, Talitha78, responded to debates over race in popular culture by creating a vid, "White' and Nerdy," focused on an African-American character on the TV show Psych. She explained: "putting this together became a way of working through my issues with regard to [fan debates over race known as] RaceFail 2009. Like Gus, I am a nerd of color in a society where nerdiness is frequently coded as 'white.' With this vid, I want to subvert that stereotype."58

Another fan, Tea F., recounted an experience running a fan fiction-based role-playing website. One of her users was a fourteen-year-old girl, "C." One day,

56 See, e.g., TWC Editor. Pattern Recognition: A Dialogue on Racism in Fan Communities, 3 J. TRANSF. WORKS \& CULTURES (2009), available at http://dx.doi.org/10.3983/twc.2009.0172.

57 See, e.g., RACEBENT DISNEY, http://racebentdisney.tumblr.com/; Racebending Revenge Fanworks Challenge, DARK AGENDA, http://darkagenda.dreamwidth.org/tag/challenge:+racebending+revenge (producing fanworks based on any source, in any medium); Chromatic Recasting, http://fanlore.org/wiki/Chromatic Recasting (listing fanworks that have recast various TV shows and movies).

58 talitha78, White and Nerdy, YouTube (Mar. 31, 2009), available at http://www.youtube.com/watch?v=Iquni9PMBMk; see also talitha78, Comment to New Psych Vid: "White" \& Nerdy (Gus) (Apr. 23, 2009, 11:56 PM), available at http://talitha78.livejournal.com/191915.html. 
C told Tea that she had to stop using the website because her English grades were too bad.

It turned out that she was getting frustrated in English class because, as a female Chinese-American immigrant, she couldn't relate to the readings in class, that were mostly written by and featuring European-American men. She much preferred writing fanfiction where she could explore other Chinese-American girl characters, rather than writing about characters and authors who had nothing in common with her and bored her to tears. After Tea discussed C's issues with her English teacher and showed the teacher C's talents, they agreed that $\mathrm{C}$ could get extra credit for writing fan fiction. $\mathrm{C}$ ultimately went to college, double-majoring in English and photography, with English as her favorite subject. Tea identified this experience - helping $\mathrm{C}$ realize that her love of fan fiction and her ability to write about her favorite books and share her writing with her friends on the Internet was "just as valuable as writing essays about old, dead white men with whom she couldn't identify" - as one of her most memorable in fandom. 59

Fandom, as a noncommercial path into making meaning, regularly empowers creators to speak out in other ways as well. As political remix artist Jonathan McIntosh notes about his experiences teaching others to remix, "[a]fter

59 OTW, supra note 32 , at 36. 
engaging in remix culture, people young and old[] find it nearly impossible to experience media in a passive or uncritical way."60 In the context of student video editing, Professor Christina Spiesel and her colleagues likewise noted that "[a]ll it takes is the experience of lifting a sound track from one clip and attaching it to another for students to know with certainty that everything on film is constructed and that they can be builders in this medium."61

This is not to say that fair use must be noncommercial to be feminist (or fair). In fact, women who start creating in fandom gain skills that they can take anywhere, including for-profit endeavors. Alice Randall's conventionally published novel is only one example of a critical use that was fair despite its commerciality. Recently, the rap group Beastie Boys engaged in a very public dispute with the makers of the girl-focused engineering toy Goldieblox.

${ }^{60}$ Henry Jenkins, DIY Video 2010: Political Remix (Part Three), Confessions of An ACA-Fan (The Official Blog of Henry Jenkis), (Nov. 17, 2010), available at http://henryjenkins.org/2010/11/diy video 2010 political remix 1.html. 61 Christina O. SPIESEl ET AL., LAW IN THE AGE OF IMAGES: THE CHALLENGE OF VISUAL LITERACY, IN CONTEMPORARY ISSUES OF THE SEMIOTICS OF LAW231, 252-53 (Anne Wagner et al. eds., 2005); see also id. at 253-54 ("[M] aking digital videos allows students to discover how easy it is to access and manipulate information today (it's all zeroes and ones), and how easy it is to represent reality in multiple ways. This in itself makes them more critical consumers of mass media; as students tell us, 'I'll never watch TV the same way again.'”). 
Goldieblox created a parody of the Beastie Boys song "Girls," whose initial lyrics include "Girls, to do the dishes; Girls, to clean up my room." 62 The GoldieBlox ad uses lyrics such as "Girls, to build a spaceship; Girls, to code the new app" instead, over images of girls engineering a Rube Goldberg-like device out of the materials at hand, including toys clearly not intended for that purpose.

Engineering is often remixing: taking what exists and using it to build something new and useful. Starting from a song that uses tired clichés to identify girls' "place" in the world and rewriting it so that girls pick their own places is exactly what we should hope for from transformative uses. And, while I'd hate to see the noncommercial worlds of fandom discounted or replaced by commercialized spaces, women have as much right to commercialize their transformative uses as the men like Richard Prince who've had their own for-profit appropriations legitimized as fair use.

62 Goldieblox, Inc. v. Beastie Boys, No. 13-cv-05428 (N.D. Cal.) (declaratory judgment action); Corynne McSherry, Girls Against Boys: What's Wrong With the (Latest) Beastie Boys Lawsuit, ElECTROnic Frontier Front, (Nov. 24, 2013), available at https://www.eff.org/deeplinks/2013/11/beastie-boysgoldieblox-fair-use-lawsuit. 


\section{New Life and New Frontiers: The Example of Vidding}

The practice of vidding, which began in the 1970s with Kandy Fong synchronizing music to slideshows from Star Trek, distills the virtues and challenges of fanworks - their transformativeness, their feminist functions, and their copyright dangers. A vid is created by editing existing footage along with music to tell a story or make an argument. The music guides the viewer's interpretation of what she's seeing. The vidding community has been particularly valuable as a "female training ground," teaching technical skills to women: web design, coding, video and image editing, and filmmaking.63 Vidding is a powerful art because it uses popular culture's own powerful images against it: by taking charge of the image, a vidder gains the ability to show the audience what she sees:

Vidding is an art that happens through editing .... What a vidder cuts out can be just as important as what she chooses to include. Entire characters and subplots can be eliminated or marginalized, so that the vid asserts the vidder's own narrative values.

Foreground can become background and vice versa. Action

63 Jesse Walker, Remixing Television, REASON MAG., August/September 2008. 
sequences might be excised in favor of character development or relationships; secondary characters might be moved into prominence. This customization of the visual text is particularly important for women and people of color, who often find their desires marginalized. In vidding, their priorities are central.64

Because they can, vidders regularly focus on developing female or feminist perspectives that aren't present in original texts. 65 For example, Obsessive24's "Piece of Me" uses a combination of DVD footage from Britney Spears's videos and other sources to explore the singer's sexualization and the simultaneous hostility and sexism she faced from giving the media exactly what it demanded from her. "While the official video to 'Piece of Me' creates fake tabloid covers and paparazzi video, Obsessive24 uses the real thing to heartbreaking effect." 66 on

64 Francesca Coppa, An Editing Room of One's Own: Vidding as Women's Work, CAmera ObSCura 123, 124 (May 2011) [hereinafter Coppa, Vidding]; cf. Robert S. Rogoyski \& Kenneth Basin, The Bloody Case that Started from a Parody: American Intellectual Property and the Pursuit of Democratic Ideals in Modern China, 16 UCLA ENT. L. REV. 237, 258-59 (2009) (discussing ways in which remix is particularly suited to "talking back" to dominant culture, in the context of Chinese citizens who otherwise lack many tools of democratic participation).

65 Francesca Coppa, Women, Star Trek, and the Early Development of Fannish Vidding, 1 J. TRANSF. WORKS \& CULTURES (2008), available at http://journal.transformativeworks.org/index.php/twc/article/view/64. 66 Coppa, Vidding, supra note 64, at 125, 127. See Test Suite of Fair Use Vids, ORGANIZATION FOR TRANSFORMATIVE WORKS, available at 
the comedic side, "Star Trek Dance Floor" powerfully criticizes the 2009 Star Trek movie - 2009's vision of the future has even fewer women than 1967's, and the vid points out that this isn't good for anyone.67

Another exemplary vid, "Women's Work," is a critique of the sexualized violence on television, using footage from the cult hit Supernatural. The vidders cut out Supernaturals male protagonists, the Winchester brothers, and focus instead on the show's marginalized female characters, most of whom exist to be victimized by the monster of the week. "Women's Work" argues that the job of these female characters is to be menaced and killed so that the brothers have evil to fight; it is also women's work to make a vid like this, which makes sexism and misogyny visible to those who might otherwise see these women as mere plot devices. ${ }^{68}$

http://transformativeworks.org/projects/vidtestsuite (obsessive24, following accepted vidding practices, purchased Spears's videos on DVD in order to create the vid, Piece of $M e$ ).

67 On the Dance Floor, YouTuBe (June 8, 2009), available at https://www.youtube.com/watch?v=deQuFc3BP74.

${ }^{68}$ Coppa, Vidding, supra note 64, at 125. 
"Women's Work" succeeded because its target was recognizable and comparatively well-known, sparking an extensive conversation in the audience about representations of women in popular media.69

Many other vids focus on the delectable male bodies presented to us by mainstream media, taking charge of them and editing them so that they appear to be involved in narratives more to the vidder's liking. As noted previously, Joanna Russ and many others have argued that writing slash is one way in which women can develop a desiring female subjectivity under conditions at least immediately of their own choosing, rather than responding to patriarchal expectations that women are objects of desire. Vidding offers similar affordances, whether the results are slash vids or something else.

As Francesca Coppa explains, "vidding lets women experience the pleasure and power of not being seen. Vidders relish the godlike control of the editing room, bending images to their will." The flip side is that vidders, and media fans generally, get to refuse the depictions that are in the text. Identifying with a female character as portrayed on screen, before fannish modification, can be dangerous:

${ }^{69}$ Sockkpuppett, New Vid - Women's Work (Supernatural), SockKPUPPETT (Aug. 13, 2007), available at http://sockkpuppett.livejournal.com/442093.html?thread=4893421\#t4893421 
one is likely to be ambushed by sexism ranging from narrative irrelevance to depictions of graphic sexual violence and murder. The powerful invisibility of the video editor - and the pleasurable invisibility of the vid spectator to whose sensibility footage has been tailored - comes as a welcome change from the pain of objectification and identification.70 While it is certainly debatable whether reversing the scopophilic gaze is a desirable end-game for feminists, ${ }^{71}$ the ability to control what an audience sees is extremely important for women. In an empirical study, women subjected to an "objectifying gaze" were more severely affected than men who were ogled. In fact, when women who'd been ogled took a math test, their performance was

70 Coppa, Vidding, supra note 64, at 126 (footnotes omitted); see also Coppa, Taxonomy, supra note 27, at 112-13 ("The advent of home filmmaking technology has allowed women to look, judge, select, edit, and manipulate images without any of the physical or social dangers historically connected to the female gaze. Vidders then share their work with other female spectators .... [T] heir audience is specifically constituted of women who have come together, not just as fans of the visual source texts, but as fans of the vidders and of vidding itself - this particular way of seeing .... Fan activities such as vidding may be crucial to theorizing the social conditions necessary for female fetishism and the safe expression of female desire.").

${ }^{71}$ Kristina Busse, Introduction: Gender and the Politics of Fan Production, 40 CINEMA J. 104, 106 (Summer 2009) (arguing against positing a feminist utopia in fandom; among other things, reversing the gaze so women look fetishistically at men may not be the right feminist goal). 
significantly worse than men's, while the gender difference in performance for men and women in the control condition wasn't significant. Men who were ogled did not suffer a decrease in performance. ${ }^{72}$ In the world as it is now, turning the tables - controlling the narrative and refusing to be on display except as a fannish pseudonym - can be a helpful corrective.

Vidding matters because it is both powerful in its ability to convey vidders' messages and marginal. Vids are still under threat from copyright owners' claims. Even when the general practice of creating fanworks is recognized by decision-makers as justifying fair use exceptions, those decisionmakers are nervous about just how much copying is at stake. ${ }^{73}$ Just as copyright doctrine generally purports to see creativity in selection, coordination, and arrangement, we can recognize vidding as a valid art form, one founded in transformativeness. The power of creating new meanings and messages from existing works frightens and confounds copyright maximalists. We should embrace that power.

72 Sarah J. Gervais et al., When What You See is What You Get: The Consequences of the Objectifying Gaze for Men and Women, 35 PSYCH. OF WOMEN Q. 5, 11-12 (2011).

73 See Rebecca Tushnet, Scary Monsters: Hybrids, Mashups, and Other Illegitimate Children, 86 NOTRE DAME L. REV. 2133, 2137-38 (2011) (describing the simultaneous embrace and disavowal of vids as fair use by the Copyright Office in the 2009 Digital Millennium Copyright Act exemption proceedings). 


\section{V.: Conclusion}

Fanworks are not alone in drawing from what's come before. As scholars have long maintained, works are always made out of other works, whether or not they wear their antecedents on their faces. But transformativeness - obvious repetition with a difference - is a regular condition of forms of creativity associated with women. Honoring women's creativity therefore requires recognizing the creativity in these sometimes derided forms. ${ }^{74}$ As Tisha Turk has noted, if we began looking at vidders as prototypical creators rather than as oddities, we would understand creativity differently and more accurately. “[T]hinking of DVDs as materials rather than 'source' might make us rethink what we mean by originality. Is a quilt only original if the quilter also made the fabric? Is a meal only from scratch if the cook grew or raised the raw materials from which it's made?"75

Along with the many other reasons to support an expansive and flexible fair use doctrine, a copyright regime in which remix is threatened with sanctions

74 See Kristina Busse, The Return of the Author: Ethos and Identity Politics, in COMPANION TO MEDIA AUTHORSHIP, 48 (Jonathan Gray and Derek Johnson eds., 2013) (using fan communities as a model for understanding and negotiating modern authorship).

75 Tisha Turk, Originality, Transformation, Repetition, (Mar. 28th, 2013), available at http://tishaturk.dreamwidth.org/13555.html. 
has particularly damaging effects on members of marginalized groups, who are already likely to be nervous about expressing themselves. ${ }^{76}$ Female fan authors and vidders have historically been reluctant to step up and claim cultural legitimacy, and legal uncertainty hinders both production of transformative works and remixers' ability to achieve mainstream recognition. ${ }^{77}$ Among other things, the special role noncommercial remix plays in culture justifies a blanket exemption for noncommercial, transformative uses, in line with Canada's new, so-called YouTube exemption, providing greater certainty for those most likely to be silenced. More generally, feminism, I would argue, needs to stand behind fair use, defending those who would speak back to existing culture. A room of one's own can be (and often enough must be) made of materials that have been borrowed, transformed, and hammered together.

76 Library of Congress Rulemaking Hearing Section 1202 (Testimony of Francesca Coppa) 0119.4-0120.4, (May 7, 2009), available at http://www.copyright.gov/1201/hearings/2009/transcripts. 77 Id. at 0120.5-0120.17. 